\title{
A model of aerosol evaporation kinetics in a thermodenuder
}

\author{
C. D. Cappa \\ Dept. of Civil and Environmental Engineering, University of California, Davis, CA, USA \\ Received: 18 September 2009 - Published in Atmos. Meas. Tech. Discuss.: 28 October 2009 \\ Revised: 21 April 2010 - Accepted: 4 May 2010 - Published: 11 May 2010
}

\begin{abstract}
Aerosol thermodenuders provide a measure of particle volatility. The information provided by a thermodenuder is fundamentally related to the kinetics of evaporation and condensation within the device. Here, a timedependent, multi-component model of particle and gas-phase mass transfer in a thermodenuder is described. This model empirically accounts for the temperature profile along the length of a typical thermodenuder and distinguishes between the influence of the heating section and of the adsorbent denuder section. It is shown that "semi-volatile" aerosol is particularly sensitive to the inclusion of an adsorbent denuder in the model. As expected, the mass loss from evaporation of particles as they pass through the thermodenuder is directly related to the compound vapor pressure, although the assumptions regarding the enthalpy of vaporization are shown to also have a large influence on the overall calculated mass thermograms. The model has been validated by comparison with previously measured mass thermograms for single-component aerosols and is shown to provide reasonable semi-quantitative agreement. The model that has been developed here can be used to provide quantitative understanding of aerosol volatility measurements of single and multi-component aerosol made using thermodenuders that include adsorbent denuder sections.
\end{abstract}

\section{Introduction}

In recent years aerosol thermodenuders have become an important tool used to assess aerosol volatility in both the lab and field (Burtscher et al., 2001; Wehner et al., 2002, 2004; Kalberer et al., 2004; An et al., 2007; Denkenberger et al., 2007; Huffman et al., 2008, 2009a, b; Saleh et al., 2008; Asa-Awuku et al., 2009; Faulhaber et al., 2009; Grieshop et

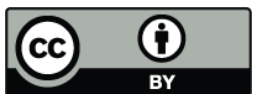

Correspondence to: C. D. Cappa (cdcappa@ucdavis.edu) al., 2009; Kostenidou et al., 2009; Kroll et al., 2009). In a typical aerosol thermodenuder (or TD), particles in a flowing air stream are heated to a fixed temperature for a specific period of time. This increase in temperature provides a driving force which induces evaporation of compounds from particles. Following the heating section, the particles are cooled and are often passed through an activated carbon denuder which is designed to (1) remove gas-phase organic species and (2) minimize re-condensation on the particles. Once the particles leave the thermodenuder they can be directed to any number of different instruments (limited only by the total flow rate required by the devices) where chemical, size or physical property measurements can be made.

With few exceptions (Saleh et al., 2008; Faulhaber et al., 2009) studies to date have used aerosol thermodenuder measurements to provide only a qualitative description of aerosol volatility. It has been previously established that the assumption that thermodynamic equilibrium at the temperature of the denuder is reached may lead to misinterpretation of observations (An et al., 2007) given that the behavior of particles in a thermodenuder is fundamentally determined by the kinetics of the evaporation process. Additionally, some have raised questions as to the need for an activated carbon section (Saleh et al., 2008). As such, quantitative understanding and interpretation of the effect of heating on particle composition necessarily requires the use of a detailed microphysical evaporation model. As particles are heated in a thermodenuder, the individual compounds comprising the particles evaporate at a rate determined by the thermodynamic properties of each individual compound (i.e. vapor pressure at ambient temperature and enthalpy of vaporization), the mole fraction of that compound within the particles (accounting for Raoult's Law) and the strength of non-ideal interactions with the other particle components. Note that implicit in this discussion is the assumption that the particles exhibit liquid-like behavior (Marcolli et al., 2004; Cappa et al., 2008), and are therefore well-mixed on the time scale of the evaporation process. In addition, mass transfer limitations, re-condensation upon

Published by Copernicus Publications on behalf of the European Geosciences Union. 
cooling and loss of gas-phase species and particles in the denuder must be accounted for.

Here, the development of a detailed kinetic model of evaporation, which can be used to quantitatively interpret measurements of organic aerosol volatility made using thermodenuders, is reported on. A useful aspect of our model is that the influence of the adsorbent denuder section of the thermodenuder has been explicitly considered, and also the velocity gradient across the thermodenuder tube has been accounted for.

\section{Kinetic model of aerosol evaporation}

A two-stage model of a thermodenuder (heated tube + denuder) has been developed for use in the analysis of TD experiments. This model can be used to explore the influence of the choice of evaporation coefficient, the volatility (vapor pressure) distribution and the enthalpy of vaporization distribution on evaporation in a thermodenuder. Details of this model are described below.

The TD model developed here is an extension of the annular diffusion denuder model of Pratsinis et al. (1989) to a cylindrical tube geometry (Gormley and Kennedy, 1949) with temperature-dependent evaporation of a multicomponent aerosol (Cappa et al., 2008). The mass balance equation for the gas-phase molecules along the $\mathrm{x}$-axis can be written as

$$
\begin{aligned}
u(r) \frac{\partial C_{\mathrm{g}, i}(r)}{\partial x}= & \frac{D_{i}}{r} \frac{\partial}{\partial r}\left[r \frac{\partial C_{\mathrm{g}, i}}{\partial r}\right]-2 \pi N_{\mathrm{p}} D_{i} d_{\mathrm{p}}(r)\left[C_{\mathrm{g}, i}(r)\right. \\
& \left.-C_{\mathrm{sat}, i}(T) \chi_{i}(r)\right] \Gamma(r, T)
\end{aligned}
$$

where $u(r)$ is the linear velocity, $C_{\mathrm{g}, i}(r)$ is the gas-phase concentration (molecules $/ \mathrm{m}^{3}$ ) of species $i, D_{i}$ is the gasphase diffusion coefficient, $d_{\mathrm{p}}(r)$ is the particle diameter, $C_{\text {sat }, i}$ is the temperature-dependent saturation concentration of species $i, N_{\mathrm{p}}$ is the particle number concentration, $\chi_{i}(r)$ is the particle phase mole fraction of species $i$ (needed to account for Raoult's Law), $r$ is the radial distance and $x$ is the direction of flow. The default assumption is that $D_{i}=3 \times 10^{-6} \mathrm{~m}^{2} / \mathrm{s}$. The first term on the right hand side describes diffusion of the gas-phase along the tube radius and the second term describes the gain/loss in gas phase molecules due to evaporation/condensation of the particles. It is assumed that diffusion along the flow axis is negligible. The linear velocity is assumed to vary as

$u(r)=\frac{2 Q(T)}{\pi a^{4}}\left[a^{2}-r^{2}\right]$,

where $Q(T)$ is the temperature-dependent volumetric flowrate and $a$ is the overall tube radius. The volumetric flowrate increases with temperature, but the shape of the velocity profile is assumed to be unaffected by the heating or cooling. $\Gamma(r, T)$ is a term which accounts for non-continuum effects in the mass transfer process and is given by

$\Gamma(T, r)=\frac{0.75 \gamma_{\mathrm{e}}(1+K n)}{K n^{2}+K n+0.283 K n \gamma_{\mathrm{e}}+0.75 \gamma_{\mathrm{e}}}$,

where $\gamma_{\mathrm{e}}$ is the evaporation coefficient (or mass accommodation coefficient) and $K n$ is the Knudsen number (Seinfeld and Pandis, 1998). The Knudsen number is defined as:

$K n=2 \lambda / d_{\mathrm{p}}$,

where $\lambda$ is the mean-free-path of the evaporating molecule in air. The radial dependence of $\Gamma$ comes from the radial dependence of $d_{\mathrm{p}}$. The mean free path is estimated as

$\lambda=3 D_{i} / v_{\mathrm{RMS}}$,

where $v_{\mathrm{RMS}}$ is the root mean square speed of the evaporating molecule, which is given by

$v_{\mathrm{RMS}}=\sqrt{8 R T / \pi \mathrm{MW}_{i}}$

with $R$ being the ideal gas constant and $\mathrm{MW}_{i}$ the molecular weight. The evaporation coefficient is defined as the ratio between the actual evaporation rate divided by the theoretical maximum evaporation rate, as given by the Hertz-Knudsen equation (Kulmala and Wagner, 2001). Unless otherwise specified, it has been assumed here that $\gamma_{\mathrm{e}}=1$ (although this value can be adjusted as desired).

For particles, the equivalent mass-balance equation is

$u(r) \frac{\partial C_{\mathrm{p}, i}(r)}{\partial x}=2 \pi D_{i} d_{\mathrm{p}}(r)\left[C_{\mathrm{g}, i}(r)-C_{\mathrm{sat}, i}(T) \chi_{i}(r)\right] \Gamma(r, T)$

where $C_{\mathrm{p}, i}$ is the particle phase concentration of species $i$ (in molecules/particle).

The saturation concentrations for use in Eq. (1) are calculated from their values at a reference temperature, $T_{\text {ref }}$, of $298.15 \mathrm{~K}$ according to

$C_{\text {sat }}\left(T_{\mathrm{d}}\right)=C_{\text {sat }}\left(T_{\text {ref }}\right)\left[\frac{T_{\text {ref }}}{T_{\mathrm{d}}}\right] \exp \left(\frac{-\Delta H_{\text {vap }}}{R}\left[\frac{1}{T_{\mathrm{d}}}-\frac{1}{T_{\text {ref }}}\right]\right)$

where $D H_{\text {vap }}$ is the (compound-specific) enthalpy of vaporization and $T_{d}$ is the actual temperature of the thermodenuder. The $C_{\mathrm{sat}}$ values are calculated explicitly at every time step of the model and depend on the specific temperature profile that is used. The saturation concentrations are related to vapor pressures through the equation

$C_{\text {sat }}=\frac{\zeta 10^{6} M W p_{\text {sat }, 1}}{R T}$

where $p_{\text {sat, } 1}$ is the sub-cooled liquid vapor pressure and $z$ is the activity coefficient (here assumed to be unity).

The initial distributions between the gas and particle phase are calculated assuming equilibrium conditions, as discussed 
further below. Starting from the initial ambient temperature gas/particle distribution, Eqs. (1) and (7) are numerically integrated forward in time (i.e. distance). To facilitate numerical integration, the system is divided into a series of concentric cylinders (i.e. of $n$ bins) each with their own $d_{\mathrm{p}}, c_{i}, C_{\mathrm{g}, i}$, etc. Throughout this analysis, $n=10$ has been used. It was determined that the model results were relatively insensitive to the use of more bins, but for smaller numbers of bins the extent of evaporation was less at a given temperature (see Fig. S1 in the Supplementary Material: http://www.atmos-meas-tech.net/3/579/2010/ amt-3-579-2010-supplement.zip). The average particle residence time in the fully heated section $\left(t_{\text {res }}\right)$ is determined based on the area-weighted average velocity and specified heated tube and denuder lengths $\left(L_{\text {hot }}\right.$ and $\left.L_{\text {denude }}\right)$. Note that because the volumetric flowrate is temperature dependent, the velocity and residence time through the heated section are temperature dependent with

$t_{\text {res }}\left(T_{\mathrm{d}}\right)=t_{\text {res }}\left(T_{\text {ref }}\right)\left[T_{\text {ref }} / T_{\mathrm{d}}\right]$.

New $\chi_{i}$ values are determined for use in the next time step based on the updated $C_{\mathrm{p}, i}$, . Similarly, the particle diameter is recalculated at each time step. Although each compound is allowed to have a unique molecular weight, the simplifying assumption that the densities of all species are the same has been made here (this assumption can be relaxed as desired).

In the TD model, particles and gases, initially in equilibrium at $T_{\text {ref }}=298 \mathrm{~K}$ (see below), are first heated to the temperature of the heated section (specified as $T_{\mathrm{d}}$ ). In the heated section, it is assumed that there is no loss of gas-phase molecules to the walls, although there is mass transport of gas-phase molecules between bins due to the formation of a radial concentration gradient. This amounts to setting a boundary condition at the wall of $C_{\mathrm{g}, i}(a)=C_{\mathrm{g}, i}\left(r_{n}\right)$, where $a$ is the tube radius and $r_{n}$ is the gas-phase concentration in the bin adjacent to the wall. The assumption of no gas-phase losses in the heated section provides for a lower limit on the extent of particle evaporation in the heated section as particle evaporation in this case will cease once the gas-phase becomes saturated.

At the end of the heated section the system is returned to $T_{\text {ref }}$; for both the heating and cooling zones in the heated section, the temperature changes were specified to take place over a distance equal to $15 \%$ of the total heated section length (Fig. 1). This distance was chosen so as to be generally consistent with the measured temperature profile in a recent thermodenuder design (Huffman et al., 2008), although it should be noted that in principle any temperature profile can be accommodated. Although a temperature profile along the length of the TD was used, the radial temperature was assumed to be constant. In a real TD, the temperature nearest the tube walls will be somewhat greater than that near the center of the tube and thus the extent of evaporation within the model may be somewhat greater than actually occurs (assuming that $T_{\mathrm{d}}$ is equal to the wall temperature).

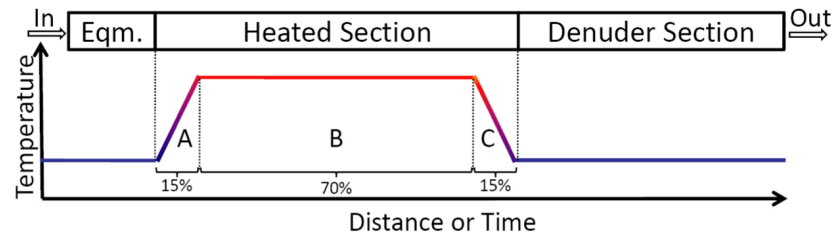

Fig. 1. Schematic of the thermodenuder model. Note that the temperature changes in the heated section take place over a distance. The heating zone is indicated by "A", the hot zone by "B" and the cooling zone by "C".

In the denuder section three different boundary conditions at the wall have been considered. In Case 1 it was assumed that the walls of the adsorbent denuder were a perfect sink for gas-phase molecules, which amounts to setting a boundary condition of $C_{\mathrm{g}, i}(a)=0$. Loss of gas-phase molecules to the walls of the adsorbent denuder leads to depletion of the gas phase near the walls and the establishment of a concentration gradient across the radial axis of the tube. This perturbation will disturb any equilibrium that might have been established in the heated region and will potentially lead to further evaporation of all compounds from the particles. In the second case a local equilibrium condition was assumed wherein the boundary condition is $C_{\mathrm{g}, i}(a)=\chi_{i} C_{\mathrm{sat}}\left(T_{\mathrm{ref}}\right)$. In this case, molecules are lost to the walls whenever $C_{\mathrm{g}, i}\left(r_{n}\right)>\chi_{i} C_{\mathrm{sat}}\left(T_{\text {ref }}\right)$ (i.e. when the system is supersaturated) but the wall loss rate falls to zero as $C_{\mathrm{g}, i}\left(r_{n}\right)$ approaches $\chi_{i} C_{\mathrm{sat}}\left(T_{\mathrm{ref}}\right)$. With this boundary condition it is implicitly assumed that the system walls are fully saturated by the compounds of interest. Experimentally, this situation may be obtained by using as a denuder a tube maintained at $T_{\text {ref }}$ (e.g. Saleh et al., 2008) as opposed to using an activated carbon denuder (e.g. Huffman et al., 2008). Both the first and second case act to decrease re-condensation of evaporated molecules onto the particles since the walls effectively act as a sink for gas-phase molecules. The extent to which re-condensation is avoided in the denuder section depends importantly on the total particle surface area (or mass loading) relative to the surface area of the walls. Finally, as a third case gas-phase loss to the denuder walls is assumed to be zero, which is an equivalent boundary condition as in the heated section. Note that in the absence of gas-phase wall losses within the denuder section the decrease in temperature from the heated section will lead to a supersaturated condition where $C_{\mathrm{g}, i}>c_{i} C_{\mathrm{sat}, i}$ and therefore lead to re-condensation onto the particles.

For all calculations here $L_{\mathrm{hot}}=58 \mathrm{~cm}$ long with $D_{\text {hot }}=2.2 \mathrm{~cm}$ and $L_{\text {denude }}$ is $41 \mathrm{~cm}$ long with $D_{\text {denude }}=1.9 \mathrm{~cm}$ (Huffman et al., 2008); as with all of the design-specific parameters used here, these can be easily adjusted to model any specific thermodenuder design. Note that the residence times reported here have been calculated based on the time spent in the fully heated region $(L=41 \mathrm{~cm})$, not including 
the heating and cooling zones. Unless otherwise specified, a flowrate of $Q=0.6 \mathrm{lpm}$, corresponding to $t_{\text {res }}=15 \mathrm{~s}$, has been used. For this design, the Reynolds number is $\sim 37$, which indicates that the assumption of Laminar flow conditions (which underlies the use of Eq. 2) is valid.

In some instances (depending on the specified vapor pressure, flow rate, temperature, etc.) the particles completely evaporate in the heated section. It has been assumed that nucleation does not occur in the system. Although nucleation may occur in real thermodenuders, it is reasonable to exclude it here because these nucleated particles will typically be easily identifiable as a mode separate from the particles of interest. The nucleated particles can therefore easily be excluded in the final analysis of real measurements that include size resolved measurements.

To produce mass thermograms, the time/distancedependent model is run once for each $T_{\mathrm{d}}$ value and from this the variation in the particle diameter, total particle mass and compound specific particle mass are determined as a function of thermodenuder temperature. Typically, the resultant particle mass values are normalized to the values at some reference temperature and thus the mass fraction remaining (MFR) can be determined as a function of temperature for comparison with experiment. A plot of MFR vs. $T_{\mathrm{d}}$ is referred to as a mass thermogram. Calculation of the MFR requires that a reference state be defined. Here, two choices of this reference state are considered: (1) where the aerosol has bypassed the thermodenuder altogether and (2) where the aerosol has passed through the entire thermodenuder at $T_{\text {ref }}$, which is equivalent to the aerosol passing only through the denuder section. These will be referred to as $\mathrm{MFR}_{\mathrm{bp}}$ and $\mathrm{MFR}_{\mathrm{d}}$, respectively. As an additional case, the MFR has been calculated for aerosol passing only through the heated section with the bypass as reference, referred to as $\mathrm{MFR}_{\mathrm{h}}$. Note that $\mathrm{MFR}_{\mathrm{bp}}$ is the parameter most directly comparable to most previously reported measurements (e.g. Huffman et al., 2008).

Particle number losses due to diffusion or thermophoresis are not explicitly accounted for in the model. Experimentally, loss of particles as they transit the TD leads to a decrease in the observed particle mass. Because the model does not account for particle losses, the calculated MFR values will be larger than might be experimentally observed. However, most experimental TD results are corrected for this particle loss (e.g. Huffman et al., 2008) and therefore the model results are, to first order, directly comparable to experimental observations. An important caveat is that, as particles are lost from the system via diffusion or thermophoresis, the total aerosol mass decreases. This perturbs the gas-particle equilibrium and will have the net effect of inducing evaporation. Since this is not explicitly accounted for here, the model results effectively provide a lower limit on the extent of evaporation at a given temperature.

The system (particles + gas-phase) are assumed to be in equilibrium when they enter the thermodenuder. The equi- librium composition of both particles and the gas-phase for a given amount of total organic mass comprised of $i$ different compounds is calculated according to absorptive partitioning theory (Pankow, 1994), where the compound specific particle mole fraction is given by (Donahue et al., 2006)

$\xi_{i}=\left(1+\mathrm{MW}_{\mathrm{OA}} C_{\mathrm{sat}, i} / \mathrm{MW}_{i} C_{\mathrm{OA}}\right)^{-1}$

where $C_{\mathrm{OA}}$ is the total organic mass loading $\left(\mu \mathrm{g} / \mathrm{m}^{3}\right), C_{\mathrm{sat}, i}$ is the effective saturation concentration of compound $i$ $\left(\mu \mathrm{g} / \mathrm{m}^{3}\right), \mathrm{MW}_{i}$ is the molecular weight of compound $i$ and $\mathrm{MW}_{\mathrm{OA}}$ is the average molecular weight of the compounds comprising the aerosol. Here, the equation given by Donahue et al. has been modified to explicitly include molecular weight.

\section{Results and discussion}

The thermodenuder model described above includes separate heated and denuder sections. A previously published model of particle evaporation in a thermodenuder considered only the heated section (Faulhaber et al., 2009). Additionally, this previous model did not account for the variable residence times experienced by particles in the heated section due to the velocity profile across the tube diameter. A different TD model (Saleh et al., 2008) did include an explicit denuder section in addition to the heated section as a test case but did not fully explore the implications. Specific aspects of our model formulation, in particular to the effects of the inclusion of the denuder section and velocity profile, are explored here. All data from Figs. 2-12 are provided as Supplementary Material (http://www.atmos-meas-tech.net/3/579/2010/ amt-3-579-2010-supplement.zip).

\subsection{Comparison with observations: testing the model}

The model has been tested by comparing with the experimental observations of Faulhaber et al. (2009), where the mass thermograms of single-component particles with known temperature-dependent vapor pressures were determined, specifically for butanedioic, hexanedioic and decanedioic acids (Fig. 2). Since Faulhaber et al. utilized a TD with an adsorbent denuder section we only consider that boundary condition (Case 1) here. There has been some disagreement in the literature over the exact temperature-dependent vapor pressures of the compounds used by Faulhaber et al. (e.g. Bilde et al., 2003; Chattopadhyay and Ziemann, 2005; Cappa et al., 2007). The observations have therefore been considered in the context of the thermodynamic parameters reported by both Chattapadhyay and Ziemann (2005) and Cappa et al. (2007) individually, as well as by using average values. The model inputs used were $d_{\mathrm{p}}=200 \mathrm{~nm}$, $C_{\mathrm{OA}}=150 \mu \mathrm{g} / \mathrm{m}^{3}, Q=0.6 \mathrm{slpm}, T_{\mathrm{ref}}=25^{\circ} \mathrm{C}$ and $\gamma_{\mathrm{e}}=1$. Because the Cappa et al. vapor pressures are lower than the Chattopadhyay et al. vapor pressures, for these compounds there 

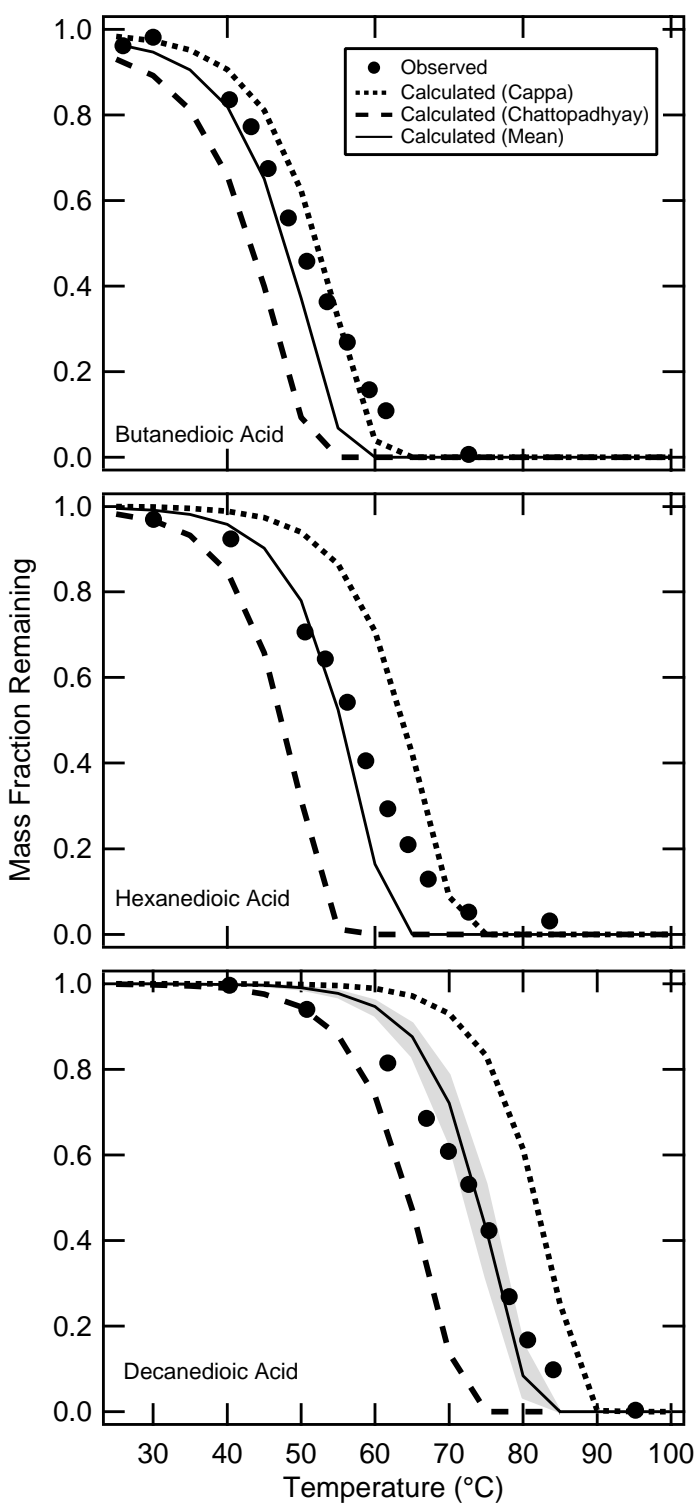

Fig. 2. Calculated mass fraction remaining (referenced to bypass) for butanedioic, hexandioic and decanedioic acid compared to observations by Faulhaber et al. (2009). The thermodynamic parameters $\left(C_{\text {sat }}\right.$ and $\left.\Delta H_{\text {vap }}\right)$ used are from Cappa et al. (2007) (dotted), Chattopadhyay and Ziemann (2005) (dashed) or the average of the two (solid). The model was run using $d_{\mathrm{p}}=200 \mathrm{~nm}, t_{\mathrm{res}}=16 \mathrm{~s}, \gamma_{\mathrm{e}}=1$ and $C_{\mathrm{OA}}=150 \mu \mathrm{g} / \mathrm{m}^{3}$. For decanedioic acid the gray region shows the range for $100 \mu \mathrm{g} / \mathrm{m}^{3}<C_{\mathrm{OA}}<200 \mu \mathrm{g} / \mathrm{m}^{3}$.

is a general tendency for more mass to remain at a given temperature when the Cappa et al. vapor pressures are used. Additionally, there is some tendency for the measured thermograms to be less steep than the calculated thermograms. Nonetheless, it is evident that the model qualitatively captures the observed TD behavior for each of the dicarboxylic acids considered, and when the average vapor pressures and $\Delta H_{\mathrm{vap}}$ 's are used semi-quantitative agreement is obtained,

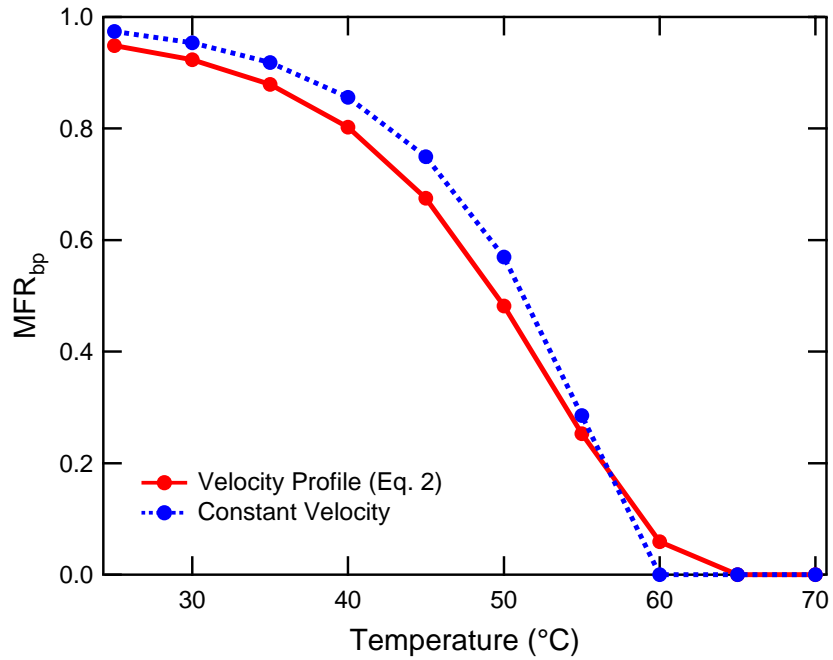

Fig. 3. The mass fraction remaining (referenced to the bypass, i.e. MFR $_{\mathrm{bp}}$ ) is shown as a function of $T_{\mathrm{d}}$ using the adsorbent denuder boundary condition (Case 1). The solid red curve shows when the laminar flow velocity profile in the thermodenuder is explicitly considered and the dotted blue curve when a flat velocity profile is assumed. The calculations assume a single-component aerosol with $d_{\mathrm{p}}=200 \mathrm{~nm}, C_{\mathrm{sat}}=5 \mu \mathrm{g} / \mathrm{m}^{3}, \Delta H_{\mathrm{vap}}=100 \mathrm{~kJ} / \mathrm{mol}, C_{\mathrm{OA}}=100 \mu \mathrm{g} / \mathrm{m}^{3}$, $\gamma_{\mathrm{e}}=1$, and $t_{\mathrm{res}}=15 \mathrm{~s}$.

thereby providing confidence in our model.

\subsection{Influence of gas velocity}

The calculated MFR is found to change somewhat more steeply with temperature when a constant velocity is assumed compared to when the velocity profile given as Eq. (2) is used (Fig. 3). This is true independent of which reference condition is used (i.e. $\mathrm{MFR}_{\mathrm{h}}$ vs. $\mathrm{MFR}_{\mathrm{bp}}$ ). The differences between the calculated constant and variable velocity MFR's can be understood by considering the differences in terms of an equivalent shift in vapor pressure and $\Delta H_{\text {vap. }}$. To produce a thermogram under constant velocity conditions that is similar to the one with the actual velocity profile for a single component aerosol results requires a decrease in the $\Delta H_{\text {vap }}$ and an increase in the vapor pressure. For the single compound example shown in Fig. $3\left(C_{\mathrm{sat}}=5 \mu \mathrm{g} / \mathrm{m}^{3}\right)$, it was necessary to decrease $\Delta H_{\text {vap }}$ by ca. $15-20 \mathrm{~kJ} / \mathrm{mol}$ (from $100 \mathrm{~kJ} / \mathrm{mol}$ ) and increase $C_{\text {sat }}$ by ca. a factor of 1.8 to bring the constant velocity thermogram into agreement with the velocity profile thermogram. For smaller values of $C_{\text {sat }}$, somewhat smaller decreases in $\Delta H_{\text {vap }}$ and greater increases in $C_{\text {sat }}$ appear to be necessary (ca. $10 \mathrm{~kJ} / \mathrm{mol}$ and a factor of three for e.g. $C_{\text {sat }}=0.01 \mu \mathrm{g} / \mathrm{m}^{3}$ ) Thus, if an average velocity (or residence time) is used rather than the actual velocity profile, the vaporization enthalpy needed to match the model with measurements will be somewhat smaller than the actual value. 

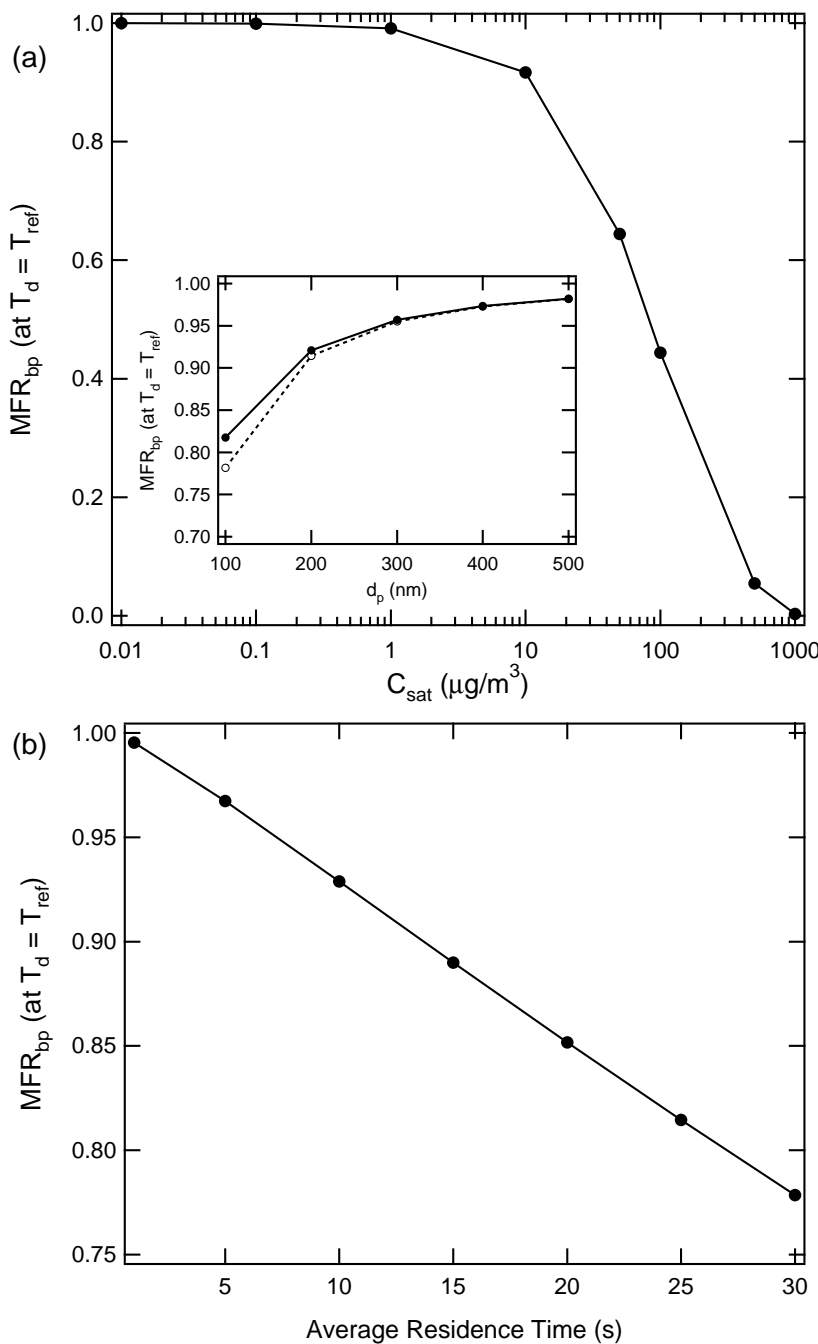

Fig. 4. (a) Calculated mass fraction remaining $\left(\mathrm{MFR}_{\mathrm{bp}}\right)$ at $T_{\mathrm{d}}=$ $T_{\text {ref (i.e. no heating) for single-component particles shown as a }}$ function of $C_{\mathrm{sat}}\left(d_{\mathrm{p}}=200 \mathrm{~nm}, C_{\mathrm{OA}}=50 \mu \mathrm{g} / \mathrm{m}^{3}\right)$ using the adsorbent denuder boundary condition (Case 1). (inset) Calculated $\mathrm{MFR}_{\mathrm{bp}}$ at $T_{\mathrm{d}}=T_{\text {ref }}$ as a function of particle diameter for $C_{\mathrm{sat}}=10 \mu \mathrm{g} / \mathrm{m}^{3}$ at two different aerosol mass loadings, $5 \mu \mathrm{g} / \mathrm{m}^{3}(\bullet)$ and $150 \mu \mathrm{g} / \mathrm{m}^{3}$ (o). (b) Calculated $\mathrm{MFR}_{\mathrm{bp}}$ at $T_{\mathrm{d}}=T_{\text {ref }}$ as a function of the residence time in the denuder $\left(C_{\mathrm{sat}}=10 \mu \mathrm{g} / \mathrm{m}^{3}, d_{\mathrm{p}}=200 \mathrm{~nm}\right.$ and $\left.C_{\mathrm{OA}}=150 \mu \mathrm{g} / \mathrm{m}^{3}\right)$.

\subsection{Influence of the denuder}

As discussed above, the role of the adsorbent denuder is to strip gas-phase molecules out of the air stream, thus leading to a decrease in the gas-phase concentration. This process can limit re-condensation, but has the negative aspect of potentially leading to further evaporation of particles after the heated section. As $C_{\mathrm{g}, i}$ is reduced due to gas-phase wall losses the particles will evaporate until such time as gas-particle equilibrium is re-established; thus, when the adsorbent denuder boundary condition is assumed gas-particle

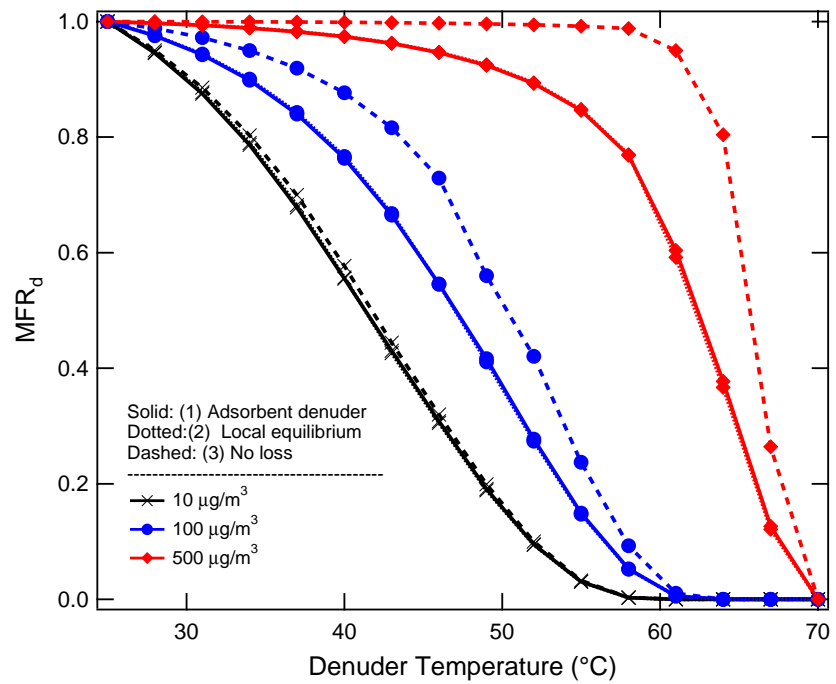

Fig. 5. The mass fraction remaining $\left(M F R_{d}\right)$ is shown for the three different wall boundary conditions considered, i.e. the adsorbent denuder (Case 1, solid lines), local equilibrium (Case 2, dotted lines) and no loss (Case 3 , dashed lines) for various $C_{\mathrm{OA}}$ assuming $C_{\text {sat }}=10 \mu \mathrm{g} / \mathrm{m}^{3}, \Delta H_{\mathrm{vap}}=90 \mathrm{~kJ} / \mathrm{mol}, t_{\mathrm{res}}=16 \mathrm{~s}, d_{\mathrm{p}}=200 \mathrm{~nm}$ and $\gamma_{\mathrm{e}}=1$ to illustrate the influence of recondensation. The results from Case 1 and Case 2 are indistinguishable. The $C_{\mathrm{OA}}$ used were $10 \mu \mathrm{g} / \mathrm{m}^{3}$ $(\times), 100 \mu \mathrm{g} / \mathrm{m}^{3}(\bullet)$ and $500 \mu \mathrm{g} / \mathrm{m}^{3}(\diamond)$. Note that $\mathrm{MFR}_{\mathrm{d}}$ is used here, i.e. the mass fraction remaining relative to the aerosol after having passed through the thermodenuder at $T_{\text {ref }}$.

equilibrium will never be achieved due to the continuous loss of gas-phase molecules to the walls. To understand the influence of the gas stripping which occurs in the adsorbent denuder, the $\mathrm{MFR}_{\mathrm{bp}}$ has been calculated with $T_{\mathrm{d}}=T_{\mathrm{ref}}$ for a single component aerosol as a function of the saturation vapor pressure. For typical thermodenuder conditions $\left(t_{\text {res }}=15 \mathrm{~s}\right)$, the presence of the denuder section has a minimal influence on the calculated MFR $\mathrm{bp}_{\mathrm{p}}$ when $C_{\mathrm{sat}}<1 \mu \mathrm{g} / \mathrm{m}^{3}$ (Fig. 4a). (Recall that it is assumed here that $\gamma_{\mathrm{e}}=1$.) However, for $C_{\mathrm{sat}}>1 \mu \mathrm{g} / \mathrm{m}^{3}$ the inclusion of the denuder leads to a decrease in $\mathrm{MFR}_{\mathrm{bp}}$ below 1. For example, for $C_{\mathrm{sat}}=10 \mu \mathrm{g} / \mathrm{m}^{3}$ $\mathrm{MFR}_{\mathrm{bp}} \sim 0.9$. For a given $C_{\mathrm{sat}}$ there is only a very small dependence on the total aerosol mass loading. There is, however, a noticeable dependence on the particle size (Fig. 4, inset). For a given $C_{\text {sat }}$ and $t_{\text {res }}$, smaller particles have a lower MFR $_{\mathrm{bp}}$ than bigger particles. This is primarily a consequence of variations in both the non-continuum term, $\Gamma$, and the surface area-to-volume ratio with particle diameter. Additionally, the calculated MFR $\mathrm{bp}_{\text {(with }} T_{\mathrm{d}}=T_{\text {ref }}$ ) depends explicitly on the residence time in the denuder (Fig. 4b). Overall, it is found that the inclusion of the adsorbent denuder section leads to evaporation of the particles, consistent with the findings of Saleh et al. (2008). The extent of evaporation depends on the compound vapor pressure, assumed evaporation coefficient, particle size and average residence time, and is predicted to be large for compounds with high vapor pressures. 
It is additionally important to consider how the denuder affects measurements made at elevated temperatures, where re-condensation is a concern. This has been explored by running calculations for the three different cases described in Sect. 2. Here, the $\mathrm{MFR}_{\mathrm{d}}$ values are compared in order to isolate the effect of re-condensation from further evaporation (i.e. the reference condition is the $C_{\mathrm{OA}}$ after passing through the entire TD at $T_{\text {ref }}$ ). Figure 5 shows that, for a given $C_{\text {sat }}$, the potential for re-condensation is greater at high loadings, which are typical of laboratory experiments. In other words, the difference between the model calculations when the walls are assumed perfectly absorbing (Case 1) or in local equilibrium (Case 2) and when the walls are assumed non-absorbing (Case 3) is greatest at high loadings. Note that there is no significant difference between Case 1 and Case 2. For ambient loadings (a few tens of $\mu \mathrm{g} / \mathrm{m}^{3}$ or less) the potential for re-condensation is found to be small, at least for the timescales considered here, which is consistent with the results of Huffman et al. (2008). This suggests that re-condensation may be more of a concern for laboratory measurements, which are commonly conducted using higher aerosol loadings (Sakurai et al., 2003). Why is this the case? At lower loadings, there is less total particle surface area available for re-condensation, which has the effect of slowing the condensation process. Consider as an example a compound that has a $C_{\mathrm{sat}}=100 \mu \mathrm{g} / \mathrm{m}^{3}$. For this single component aerosol, when $C_{\mathrm{OA}}=150 \mu \mathrm{g} / \mathrm{m}^{3}$ the equilibrium gas-phase concentration is $C_{\text {gas }}=100 \mu \mathrm{g} / \mathrm{m}^{3}$; when $C_{\mathrm{OA}}=15 \mu \mathrm{g} / \mathrm{m}^{3} C_{\text {gas }}$ still equals $100 \mu \mathrm{g} / \mathrm{m}^{3}$. The gas-phase concentration has not changed but the particle mass (and therefore surface area, assuming a fixed particle size) has decreased by a factor of 10 and thus the re-condensation rate is slower. Note also that for the non-absorbing case (Case 3) the $\mathrm{MFR}_{\mathrm{d}}$ still eventually goes to zero. This occurs when all particles have completely evaporated in the heated section and, since nucleation is not allowed in the model, there is no particle surface area available for re-condensation. It is important to recognize that these calculations were performed to assess the potential influence of re-condensation, separate from evaporation within the denuder induced via loss of gasphase molecules to the walls. For the adsorbent denuder case (Case 1), this further evaporation can be significant for high $C_{\text {sat }}$ compounds and can impart a negative bias in the measured $\mathrm{MFR}_{\mathrm{bp}}$ relative to the condition at the end of the heated section (cf. Fig. 3). However, for the local equilibrium case (Case 2) there is a limit to the amount of loss of gas-phase molecules to the walls and thus further evaporation due to gas-stripping in the denuder section is minimized.

This balance between re-condensation and evaporation can be visualized more explicitly by examining the timedependent output from the model at a given temperature, specifically using the particle radius as a metric (Fig. 6). As expected, those particles closest to the walls are affected most strongly, both in the heated section and the denuder section, due to their longer residence times compared to parti- cles near the center of the tube (note that the temperature profile is assumed to be constant at all radial positions in the heater and denuder). Although two specific cases have been selected for consideration here (a high $C_{\text {sat }}$, high $C_{\mathrm{OA}}$ case and a low $C_{\mathrm{sat}}$, low $C_{\mathrm{OA}}$ case), a larger set of runs (not shown) indicates that $C_{\mathrm{OA}}$ plays a more important role than $C_{\text {sat }}$ in determining the influence of re-condensation (although $C_{\text {sat }}$ is most important for determining the amount of evaporation induced by gas-phase wall loss in the denuder section). This result arises because at higher $C_{\mathrm{OA}}$ the available particle surface is larger than at low $C_{\mathrm{OA}}$, as discussed above.

Of additional interest, the calculations indicate that it is possible to have some particles completely evaporate while others retain some mass while transiting the thermodenuder, i.e. particle number losses are possible. This is a result of there being a radial velocity gradient (recall that the radial temperature profile is assumed flat). Thus, particles closest to the wall may evaporate completely while those near the center of the tube may persist. Radial diffusion of particles, which is not explicitly considered here, will serve to decrease the actual extent of evaporation-induced particle number loss. This evaporation-induced particle loss should not be confused with particle losses at elevated temperatures due to thermophoresis (which is not explicitly accounted for here), or with the enhancement of diffusion losses that results as particles shrink and become more diffusive. This result is consistent with the experimental results of Huffman et al. (2008), who showed number losses that increased as the initial particle size decreased. These results suggest that care must be taken in correcting thermodenuder experiments for particle number losses. Such corrections are best done by characterizing a given TD using a "non-volatile" aerosol which is not subject to the evaporation-induced losses, as in Huffman et al. (2008).

The question of whether the equilibrium assumption is ever appropriate to use to interpret thermodenuder measurements has also been considered here. Here, "equilibrium assumption" specifically refers to the idea that the system (particles + gas) will equilibrate at the temperature of the heated section and remain in this state until some measurement (e.g. size, composition, etc.) is performed. It has previously been suggested that if a thermodenuder with sufficiently long residence time is used then the equilibrium assumption becomes valid (An et al., 2007). However, the cooling section and presence of an adsorbent denuder (Case 1) in some TD's means that the system may not emerge at the equilibrium condition of the heater temperature no matter how long the residence time. When the residence time in the heated section is increased, it is also increased by a proportional amount in the denuder section, at least for a fixed TD configuration. As such, the influence of the denuder will be greater at longer $t_{\text {res }}$. High volatility compounds (ca. $C_{\text {sat }}>10^{2} \mu \mathrm{g} / \mathrm{m}^{3}$ ) may come to equilibrium on a reasonably short timescale (10s of seconds) in the heated section, but it is these high volatility 


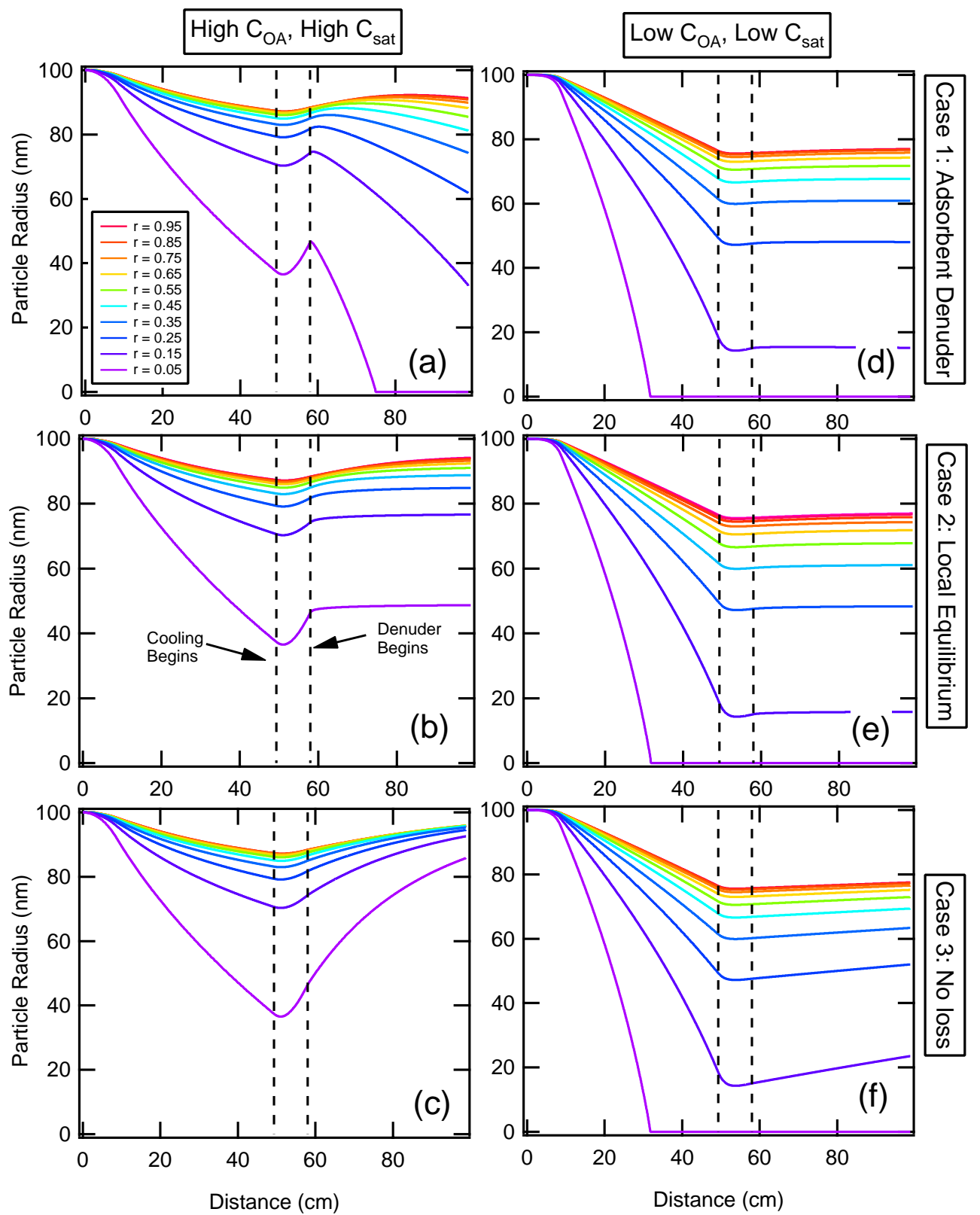

Fig. 6. The modeled variation in particle radius is shown as a function of the distance along the thermodenuder. The different curves in each panel correspond to particles that are closer to/further from the thermodenuder walls (line colors indicate the relative distance of that bin from the wall). Panels aligned vertically are for the same $C_{\text {sat }}$ while panels aligned horizontally have the same denuder boundary condition. The left panels $(\mathbf{a}, \mathbf{b}$ and $\mathbf{c})$ are for $C_{\mathrm{sat}}\left(25^{\circ} \mathrm{C}\right)=100 \mu \mathrm{g} / \mathrm{m}^{3}$ at $T_{\mathrm{d}}=35^{\circ} \mathrm{C}, C_{\mathrm{OA}}=150 \mu \mathrm{g} / \mathrm{m}^{3}$ and $\Delta H_{\mathrm{vap}} 60 \mathrm{~kJ} / \mathrm{mol} \mathrm{while}$ the right panels $(\mathbf{d}, \mathbf{e}$ and f) are for $C_{\text {sat }}\left(25^{\circ} \mathrm{C}\right)=1 \mu \mathrm{g} / \mathrm{m}^{3}$ at $60^{\circ} \mathrm{C}, C_{\mathrm{OA}}=15 \mu \mathrm{g} / \mathrm{m}^{3}$ and $\Delta H_{\mathrm{vap}} 120 \mathrm{~kJ} / \mathrm{mol}$. The top panels (a and d) correspond to the adsorbent denuder (Case 1), the middle panels (b and e) to the local equilibrium (Case 2) and the bottom panels (c and f) to no loss (Case 3). In all cases $t_{\text {res }}=15 \mathrm{~s}$ and $\gamma_{\mathrm{e}}=1$. The vertical dashed lines indicate the point where the cooling begins (left) and the denuder section begins (right).

compounds that are most sensitive to gas-stripping in the denuder. Low volatility compounds are not all that sensitive to the denuder section, however they will not reach equilibrium in the heated section in any reasonable (i.e. experimentally accessible) time period. In contrast, when the local equilibrium condition is assumed (Case 2), gas-stripping in the denuder section is no longer a concern and the particles can theoretically reach an equilibrium state that is close to that at the exit of the heated section.

The time to reach equilibrium also depends importantly on the associated particle mass loading. Considering only evaporation in the heated section (i.e. the $M F R_{h}$ ), for a 


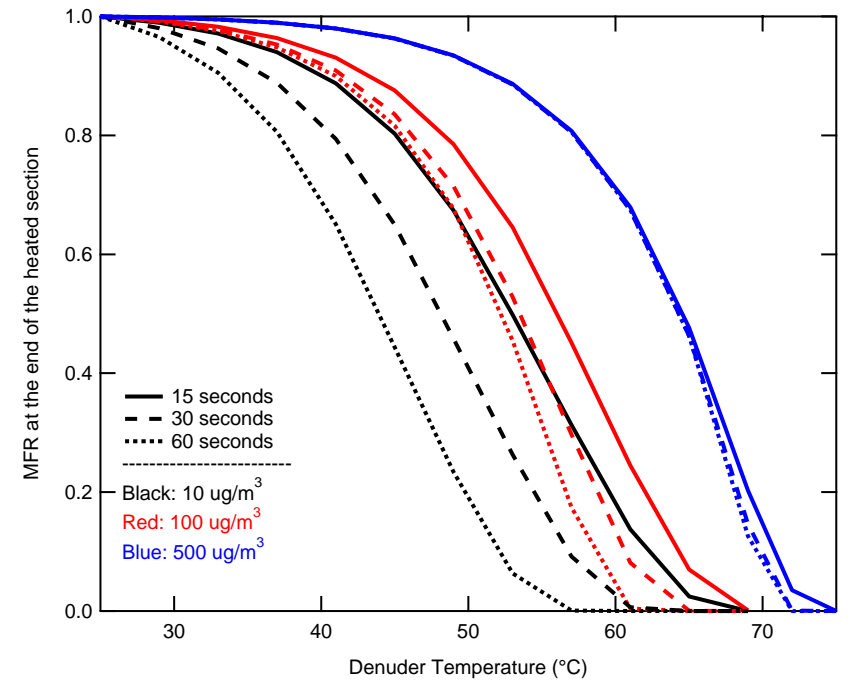

Fig. 7. The calculated mass fraction remaining at the end of the heated section $\left(\mathrm{MFR}_{\mathrm{h}}\right)$ is shown as a function of $T_{\mathrm{d}}$ for a single compound aerosol with $C_{\mathrm{sat}}=1 \mu \mathrm{g} / \mathrm{m}^{3} \quad\left(\Delta H_{\mathrm{vap}}=120 \mathrm{~kJ} / \mathrm{mol}\right.$, $d_{\mathrm{p}}=200 \mathrm{~nm}$ ) for different $C_{\mathrm{OA}}$ values and different $t_{\mathrm{res}}$ (see legend for specific values).

relatively low-volatility compound with $C_{\mathrm{sat}}=1 \mu \mathrm{g} / \mathrm{m}^{3}$ with $\Delta H_{\text {vap }}=120 \mathrm{~kJ} / \mathrm{mol}$, when $C_{\mathrm{OA}}=10 \mu \mathrm{g} / \mathrm{m}^{3}$ the system does not reach equilibrium in the heated section even after $60 \mathrm{~s}$ (Fig. 7). Yet when $C_{\mathrm{OA}}=500 \mu \mathrm{g} / \mathrm{m}^{3}$ they system rapidly reaches equilibrium (Fig. 7). This result can be understood by considering the overall volume available per particle, equal to $1 / N_{p}$, the amount of material that must evaporate to saturate the gas-phase at a given temperature relative to the amount available for evaporation, and the surface area available for evaporation. For example, at $T_{\mathrm{d}}=35^{\circ} \mathrm{C}, C_{\text {sat }}$ increases from $1 \mu \mathrm{g} / \mathrm{m}^{3}\left(25^{\circ} \mathrm{C}\right)$ to $9.7 \mu \mathrm{g} / \mathrm{m}^{3}$. Thus, when $C_{\mathrm{OA}}=10 \mu \mathrm{g} / \mathrm{m}^{3}$, most of the available particle-phase material must evaporate for the system to reach equilibrium. In contrast, when $C_{\mathrm{OA}}=500 \mu \mathrm{g} / \mathrm{m}^{3}$ only a small amount of the available material must evaporate and additionally the surface area available is 50 times greater than when $C_{\mathrm{OA}}=10 \mu \mathrm{g} / \mathrm{m}^{3}$, which means that the overall evaporation rate (as opposed to the per particle evaporation rate) is effectively 50 times greater and the evaporation of the additional $8.7 \mu \mathrm{g} / \mathrm{m}^{3}$ worth of material will occur much more rapidly.

\subsection{Influence of the thermodynamic properties of the aerosol components}

Mass thermograms for single component aerosol with different saturation vapor pressures $\left(C_{\text {sat }}\right)$ and a fixed $\Delta H_{\text {vap }}$ (Fig. 8a) have been calculated for the adsorbent denuder condition (Case 1). As expected, the temperature that must be reached in the thermal denuder to cause complete evaporation of the particles varies inversely with vapor pressure. More specifically, the model indicates that there is a linear relationship between $\log \left(C_{\mathrm{sat}}\right)$ and $1 / T_{50}$ (Fig. 8c) where $T_{50}$ is the temperature where $\mathrm{MFR}_{\mathrm{bp}}=0.5$. This is similar to what was determined previously by Faulhaber et al. (2009); depending upon the assumed $\Delta H_{\mathrm{vap}}, d_{\mathrm{p}}, D_{i}$, etc., quantitative agreement between the model and the Faulhaber et al. results can be obtained (Fig. 8c). (Note that this relationship breaks down somewhat at high $C_{\text {sat }}$ if $\mathrm{MFR}_{\mathrm{d}}$ is instead considered).

The influence of the choice of $\Delta H_{\text {vap }}$ for a fixed $C_{\text {sat }}$ on the calculated mass thermogram has been explored as well (Fig. 8b). Interestingly, for a fixed $C_{\text {sat }}, T_{50}$ and $\Delta H_{\text {vap }}$ have a relationship that can be best be described through a power law with $\Delta H_{\mathrm{vap}}=a+b \times T_{50}^{p}$ (Fig. 8d). The parameters $a$ and $b$ are not unique as they depend on the assumed $C_{\mathrm{sat}}, C_{\mathrm{OA}}$, $d_{\mathrm{p}}$, etc., and therefore they are not reported here. However, in general for low $\Delta H_{\text {vap }}$ small changes in $\Delta H_{\text {vap }}$ are predicted to have a large influence on the $T_{50}$ while at high $\Delta H_{\text {vap }}$ comparably large changes are needed to cause even small changes in $T_{50}$ (Fig. 8c). For example, if $\Delta H_{\text {vap }}$ is changed from $50 \mathrm{~kJ} / \mathrm{mol}$ to $60 \mathrm{~kJ} / \mathrm{mol}, T_{50}$ changes by more than $25^{\circ} \mathrm{C}$ (for $C_{\text {sat }}=1 \mu \mathrm{g} / \mathrm{m}^{3}, C_{\mathrm{OA}}=50 \mu \mathrm{g} / \mathrm{m}^{3}, t_{\text {res }}=15 \mathrm{~s}$ and $d_{\mathrm{p}}=300 \mathrm{~nm}$ ). This is equivalent to an order of magnitude change in $C_{\mathrm{sat}}$. Clearly, results from thermodenuder studies must be considered in the context of temperature-dependent volatilities and not only in terms of the volatility of the various components near room temperature (where aerosol yield experiments are typically conducted). Improved characterization of $\Delta H_{\text {vap }}$ for atmospherically-realistic compounds, such as that by Epstein et al. (2010), and mixtures is critically needed to interpret ambient TD data quantitatively.

\subsection{Influence of physical properties: size and diffusion}

The influences of particle size and mass loading on the calculated $T_{50}$ were both investigated for the adsorbent denuder condition (Case 1). At low mass loadings, the $T_{50}$ decreased monotonically with particle diameter (Fig. 9). At higher loadings the $T_{50}$ decreased with $d_{\mathrm{p}}$ for large diameters, but became relatively insensitive to changes in particle diameter for small $d_{\mathrm{p}}$. This is somewhat different than was found for the room temperature (i.e. denuder-only) calculations above, where only a weak dependence on mass loading was found. As with the time needed to reach equilibrium discussed above, this difference arises in large part because the particle number concentration increases with $C_{\mathrm{OA}}$ (for a fixed $d_{\mathrm{p}}$ ), and each particle has a smaller overall volume available for evaporation (equal to $1 / N_{\mathrm{p}}$ ). As temperature is increased and evaporation occurs, the gas-phase will become saturated more rapidly at higher mass loadings due to the smaller available overall volume per particle. Consequently, the magnitude of mass loss for a given temperature will scale inversely with loading, which is observed as an increase in the $T_{50}$ with $C_{\mathrm{OA}}$ (for a given $d_{\mathrm{p}}$ ). This is consistent with the observations of Faulhaber et al. (2009). This loading effect does not apply in the same way to the room temperature (denuder-only) calculations because the driving force for 

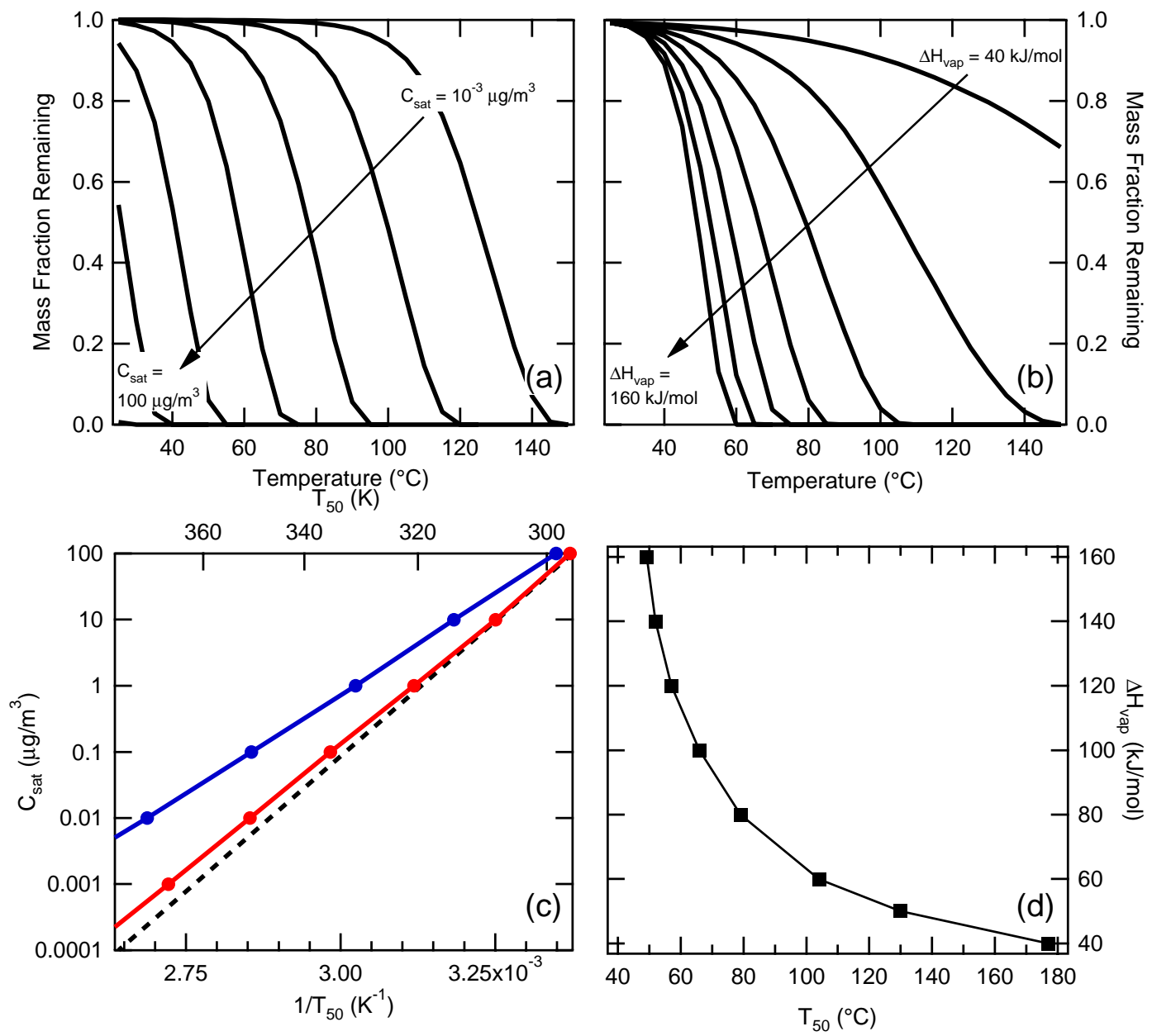

Fig. 8. (a) The calculated mass fraction remaining $\left(\mathrm{MFR}_{\mathrm{bp}}\right)$ for particles passed through a thermal denuder is shown for different values of $C_{\text {sat }}$, ranging from $C_{\mathrm{sat}}=0.01$ to $100 \mu \mathrm{g} / \mathrm{m}^{3}$. The adsorbent denuder boundary condition (Case 1) was used. Here, it was assumed that $d_{\mathrm{p}}=300 \mathrm{~nm}, t_{\mathrm{res}}=15 \mathrm{~s}, \Delta H_{\mathrm{vap}}=120 \mathrm{~kJ} / \mathrm{mol}, C_{\mathrm{OA}}=50 \mu \mathrm{g} / \mathrm{m}^{3}$ and $\gamma_{\mathrm{e}}=1$. (b) Same as (a), but where the $\Delta H_{\mathrm{vap}}$ values were varied from

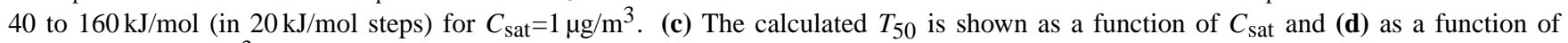
$\Delta H_{\mathrm{vap}}\left(C_{\mathrm{sat}}=1 \mu \mathrm{g} / \mathrm{m}^{3}, d_{\mathrm{p}}=300 \mathrm{~nm}\right)$. For (c), the calculations used $\Delta H_{\mathrm{vap}}=120 \mathrm{~kJ} / \mathrm{mol}$ and $d_{\mathrm{p}}=300 \mathrm{~nm}\left(\mathrm{blue}\right.$ line) or $\Delta H_{\mathrm{vap}}=150 \mathrm{~kJ} / \mathrm{mol}$ and $d_{\mathrm{p}}=200 \mathrm{~nm}$ (red line). Note that $T_{50}$ values in (c) are in K. The experimental $C_{\text {sat }}$ vs. $1 / T_{50}$ relationship determined by Faulhaber et al. (2009) is shown for reference (dashed line). A MW of $150 \mathrm{~g} / \mathrm{mol}$ was assumed to convert vapor pressure to $C_{\text {sat }}$.

evaporation is actually removal of gas-phase molecules by the denuder. The gas-phase in the denuder will not become saturated no matter how small the overall volume per particle, and thus there is a negligible dependence of $\operatorname{MFR}\left(T_{\text {ref }}\right)$ on $C_{\mathrm{OA}}$. Additionally, it was determined that the general form of the dependence of $T_{50}$ on $d_{\mathrm{p}}$ was independent of $\Delta H_{\text {vap }}$, although $\Delta H_{\text {vap }}$ does have an influence on the absolute $T_{50}$ values.

The sensitivity of the calculations to the assumed gasphase diffusion coefficient was also determined (Fig. 10). As expected, $T_{50}$ increases as $D_{i}$ decreases. The general form of the relationship between $D_{i}$ and $T_{50}$ is essentially independent of $d_{\mathrm{p}}$, mass loading and $\Delta H_{\mathrm{vap}}$, although the absolute range over which $T_{50}$ varies does depend on these variables. The $D_{i}$ vs. $T_{50}$ relationship is non-linear, with a higher sen- sitivity for smaller $D_{i}$. It is difficult to come up with a generally applicable uncertainty estimate based on the uncertainty in $D_{i}$ because this will depend on the specific conditions $\left(d_{\mathrm{p}}\right.$, $C_{\mathrm{OA}}$ and $\left.\Delta H_{\mathrm{vap}}\right)$. However, if it is assumed that $D_{i}$ can be known to within $\pm 20 \%$, it can be seen in Fig. 10 that the associated variability in $T_{50}$ ranges from much less than a degree up to a few degrees.

Actual atmospheric particles will likely contain nonorganic material, some of which may be considered volatile above some critical temperature (e.g. sulfate) or completely non-volatile (e.g. black carbon). To address this, the influence of having particles containing a non-volatile core has also been considered. For a fixed total $C_{\mathrm{OA}}$ and $d_{\mathrm{p}}$ this has the effect of increasing the total number of particles, and therefore the surface area available for evaporation. 


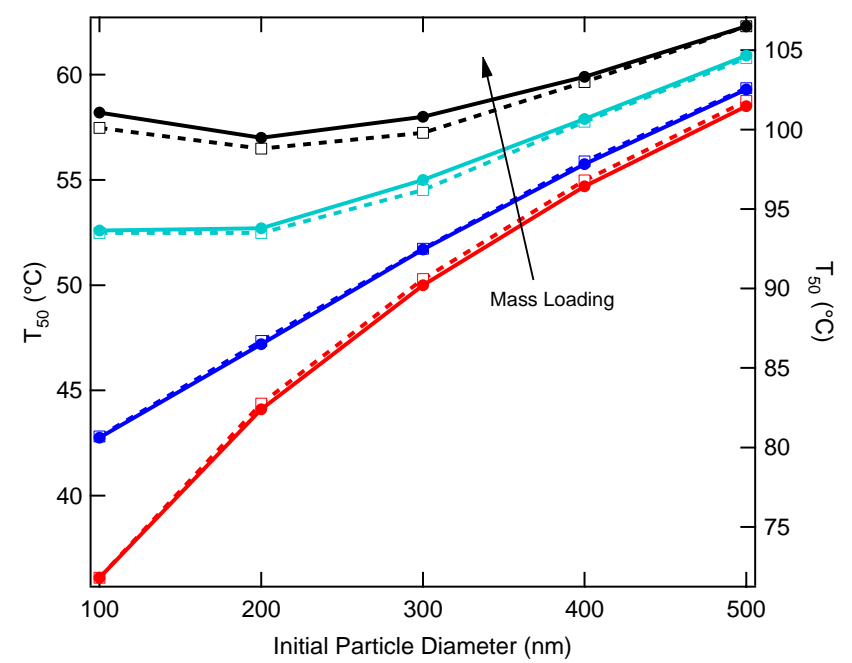

Fig. 9. Calculated dependence of $T_{50}$ on the initial particle diameter, $d_{\mathrm{p}}$, using the adsorbent denuder boundary condition (Case 1). The different color lines correspond to different aerosol mass loadings $\left(5 \mu \mathrm{g} / \mathrm{m}^{3}, 50 \mu \mathrm{g} / \mathrm{m}^{3}, 150 \mu \mathrm{g} / \mathrm{m}^{3}\right.$ and $\left.250 \mu \mathrm{g} / \mathrm{m}^{3}\right)$. The saturation concentrations used were either $C_{\mathrm{sat}}=5 \mu \mathrm{g} / \mathrm{m}^{3}$ (solid lines, left axis) or $C_{\mathrm{sat}}=0.1 \mu \mathrm{g} / \mathrm{m}^{3}$ (dashed lines, right axis). For these calculations, $\Delta H_{\mathrm{vap}}=100 \mathrm{~kJ} / \mathrm{mol}, D_{i}=3 \times 10^{-6} \mathrm{~m}^{2} / \mathrm{s}$ and $t_{\mathrm{res}}=15 \mathrm{~s}$.

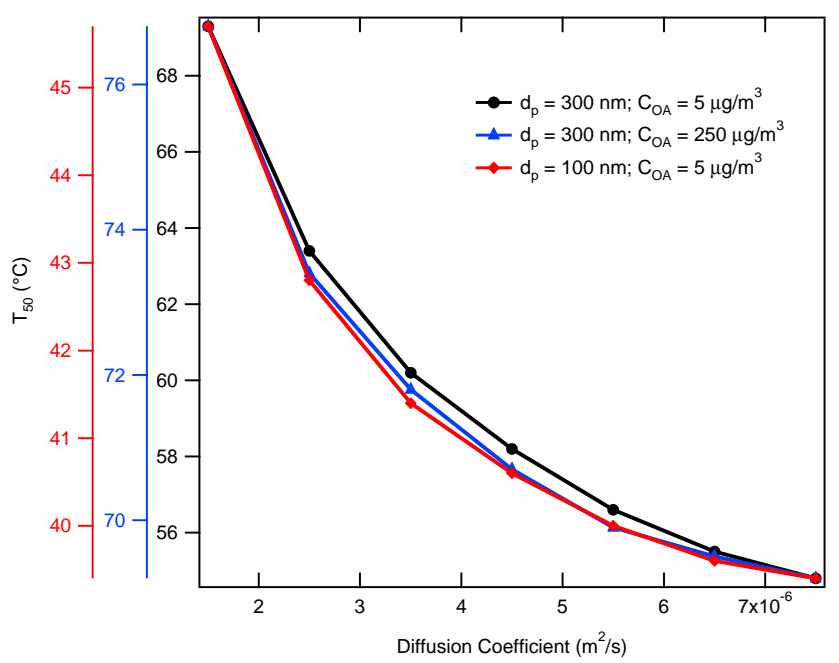

Fig. 10. Calculated dependence of $T_{50}$ on the diffusion coefficient using the adsorbent denuder boundary condition (Case 1). The line colors correspond to the axis colors and were for (black) $d_{\mathrm{p}}=300 \mathrm{~nm}$ and $C_{\mathrm{OA}}=5 \mu \mathrm{g} / \mathrm{m}^{3}$, (blue) $d_{\mathrm{p}}=300 \mathrm{~nm}$ and $C_{\mathrm{OA}}=250 \mu \mathrm{g} / \mathrm{m}^{3}$ and (red) $d_{\mathrm{p}}=100 \mathrm{~nm}$ and $C_{\mathrm{OA}}=5 \mu \mathrm{g} / \mathrm{m}^{3}$. In all cases, $\Delta H_{\mathrm{vap}}=75 \mathrm{~kJ} / \mathrm{mol}, C_{\mathrm{sat}}=5 \mu \mathrm{g} / \mathrm{m}^{3}$ and $t_{\mathrm{res}}=15 \mathrm{~s}$. The general form of the relationship between $T_{50}$ and $D_{i}$ is relatively insensitive to the specific conditions (e.g. $\Delta H_{\mathrm{vap}}, d_{\mathrm{p}}, C_{\mathrm{OA}}$ ), although the absolute range over which $T_{50}$ varies depends on these parameters.

Thus, evaporation of the volatile components is expected to proceed faster. Indeed, this is what is found. As the mass (or mole) fraction of the non-volatile component is increased
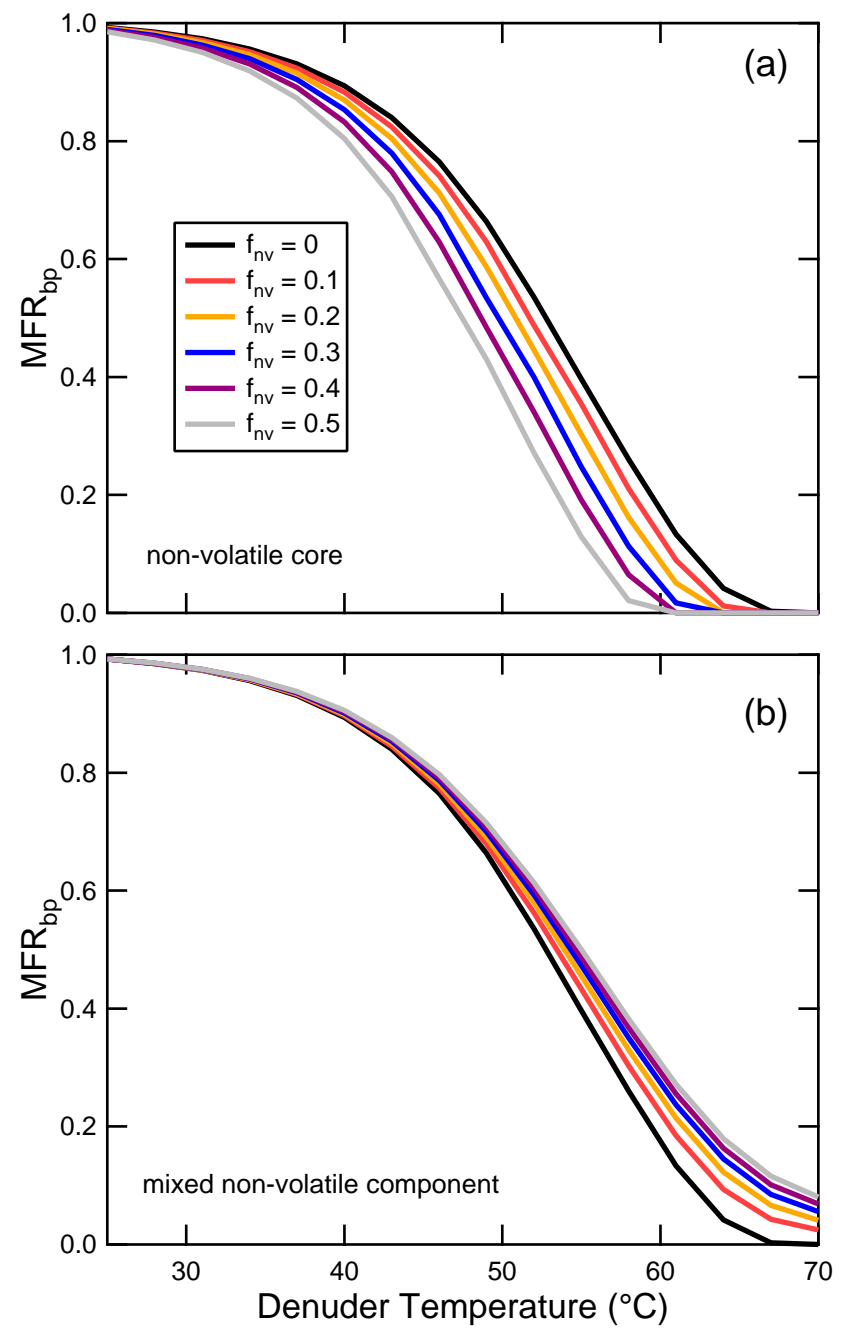

Fig. 11. (a) The $\mathrm{MFR}_{\mathrm{bp}}$ vs. $T_{\mathrm{d}}$ is shown for particles where it is assumed that a non-volatile core comprising varying fractions of the total particle mass $\left(f_{\mathrm{nv}}\right)$ is included. The calculations used $C_{\mathrm{sat}}=1 \mu \mathrm{g} / \mathrm{m}^{3}, C_{\mathrm{OA}}=10 \mu \mathrm{g} / \mathrm{m}^{3}, \Delta H_{\mathrm{vap}}=120 \mathrm{~kJ} / \mathrm{mol}$ and $d_{\mathrm{p}}=200 \mathrm{~nm}$. (b) Same as (a), but for the condition where the nonvolatile fraction participates in absorptive partitioning, i.e. is wellmixed with the volatile component. Here, the initial mass loading of the volatile component is fixed at $10 \mu \mathrm{g} / \mathrm{m}^{3}$.

the MFR at a given temperature decreases. An example of this is shown in Fig. 11a for $C_{\mathrm{OA}}=10 \mu \mathrm{g} / \mathrm{m}^{3}, C_{\text {sat }}=1 \mu \mathrm{g} / \mathrm{m}^{3}$, $\Delta H_{\mathrm{vap}}=120 \mathrm{~kJ} / \mathrm{mol}$ and $d_{\mathrm{p}}=200 \mathrm{~nm}$, where the fraction of the particle that is non-volatile, $f_{\mathrm{nv}}$, was varied from $0 \%$ to $50 \%$ of the total particle mass. Because the core does not actively mix with the volatile components in this formulation there is no Raoult's law depression of the volatile component vapor pressure, and thus the primary influence of the nonvolatile core is to change $N_{\mathrm{p}}$. Alternatively, if it is assumed that there is a non-volatile component that still is able to influence the gas-particle partitioning (i.e. is absorptive), then the evaporation dynamics are influenced by the increase in 


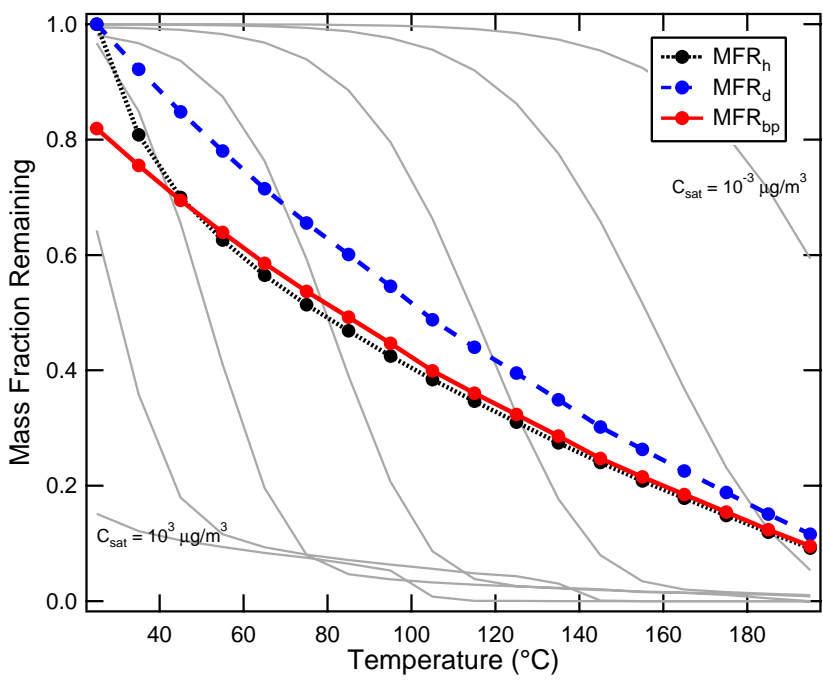

Fig. 12. Calculated mass fraction remaining for an equimass mixture of compounds where the reference state is the bypass $\left(\mathrm{MFR}_{\mathrm{bp}}\right.$, solid red line), denuder $\left(\mathrm{MFR}_{\mathrm{d}}\right.$, dashed blue line) or heated tubeonly $\left(\mathrm{MFR}_{\mathrm{h}}\right.$, dotted black line) and the adsorbent denuder boundary condition (Case 1) has been used. The $C_{\text {sat }}$ values ranged from $10^{-3}$ to $1000 \mu \mathrm{g} / \mathrm{m}^{3}$. Mass thermograms are also shown for the individual compounds comprising the aerosol as they evaporate from the mixture (thin gray lines). Here, $\Delta H_{\mathrm{vap}}=80 \mathrm{~kJ} / \mathrm{mol}, \gamma_{\mathrm{e}}=1$, $t_{\text {res }}=15 \mathrm{~s}, C_{\mathrm{OA}}=21 \mu \mathrm{g} / \mathrm{m}^{3}$ and $d_{\mathrm{p}}=300 \mathrm{~nm}$.

particle number, as above, but also by an effective decrease in the volatile compound vapor pressure via Raoult's law. In this case, the calculated MFR increases at a given temperature, indicating that the Raoult's law vapor pressure depression outweighs the increase in particle number/surface area (Fig. 11b). Thus, the influence of non-volatile material on the evaporation of volatile organic material depends importantly on the extent of internal mixing and also the exact internal mixing configuration (e.g. core-shell vs. absorptive/mixed but non-volatile).

\subsection{Multi-component aerosol}

The model which has been developed is not limited to singlecomponent aerosols, but can be used to describe the evaporation behavior of individual components from a multicomponent aerosol. As such, the model may find use in interpreting both laboratory thermodenuder measurements of primary or secondary organic aerosol or field observations. As an example of the general utility of the model for use with multi-component aerosol, a theoretical mass thermogram has been calculated for a 7-component aerosol with compounds having saturation concentrations ranging from $10^{-3}$ to $10^{3} \mu \mathrm{g} / \mathrm{m}^{3}$. For simplicity, in this example it has been assumed that the aerosol contains equal parts by mass of each component at the initial equilibrium condition and also that each compound has the same $\Delta H_{\text {vap }}(=90 \mathrm{~kJ} / \mathrm{mol})$, although semi-empirical relationships such as that given by Epstein et al. (2010) can be implemented. Figure 12 shows the calculated total mass fraction remaining for this theoretical multicomponent aerosol for the three different reference conditions (i.e. bypass, denuder and heated tube-only) for Case 1 .

As expected, the more volatile components begin to evaporate from the particles at lower temperatures than the less volatile components. Because the aerosol here is comprised of compounds with a distribution of vapor pressures, the overall mass thermogram extends over a wide range of temperatures and is not nearly as sharp as that for the individual components (Fig. 12).

The calculated MFR $_{\mathrm{bp}}$ suggests that there should be mass loss observed at ambient temperature due to evaporation of the higher-volatility components in the denuder section, if such compounds constitute a significant fraction of the sampled aerosol. Additionally, at high temperatures $\mathrm{MFR}_{\mathrm{bp}}$ and $\mathrm{MFR}_{\mathrm{h}}$ give similar results. This can be understood in the context of what is shown in Fig. 6. At higher temperatures, the "high-volatility" material has already evaporated. Once that occurs, the denuder section primarily serves to limit recondensation and, at low loadings, re-condensation is not a major concern (at least on the timescales considered here, as discussed above).

\subsection{The evaporation coefficient}

It is generally accepted that for individual organic compounds the evaporation coefficient is unity (or very close) (Kulmala and Wagner, 2001) and, for comparison, the evaporation coefficient for water is similarly large (values range from ca. 0.3 to 1) (Li et al., 2001; Winkler et al., 2004; Smith et al., 2006). An evaporation coefficient less than one indicates that there is a strong barrier to the formation of the "critical" surface species that precedes evaporation (Davidovits et al., 2006). (Recall that the evaporation coefficient is defined as a deviation from the theoretical maximum evaporation rate. That theoretical maximum is directly proportional to the vapor pressure, which is an equilibrium property describing the energetic difference between the vapor and bulk liquid, and thus is independent of the surface.) However, recently it has been suggested that the evaporation coefficient, $\gamma_{\mathrm{e}}$, for complex organic aerosol, specifically lubricating oil and secondary organic aerosol from the $\alpha$-pinene $+\mathrm{O}_{3}$ reaction, is significantly less than one $\left(0.001<\gamma_{\mathrm{e}}<0.01\right)$ (Grieshop et al., 2007; Grieshop et al., 2009) and may be less than one for individual organic acids (Saleh et al., 2009). If $\gamma_{\mathrm{e}}$ is small, this would have the effect of decreasing the evaporation rate for a compound with a given $C_{\text {sat }}$ value. For example, a compound with $C_{\mathrm{sat}}=100 \mu \mathrm{g} / \mathrm{m}^{3}$, which is predicted to evaporate significantly in the thermodenuder at room temperature, would not be observed to evaporate significantly at the same temperatures for typical experimental timescales if $\gamma_{\mathrm{e}}<0.01$. For systems where the temperature dependent vapor pressures of the individual aerosol 
components of a multi-component mixture are known a priori, the model developed here can, in theory, be used to determine the evaporation coefficient (although there may be some challenges associated with differentiating the effects of non-ideal solution behavior, e.g. Cappa et al. (2008), and evaporation coefficients that differ from unity). However, in order to determine temperature dependent vapor pressures for unknown systems, it is necessary to specify some value of $\gamma_{\mathrm{e}}$ and then to work within this constraint. Further work is certainly needed to properly constrain the probable value (or values) of $\gamma_{\mathrm{e}}$ for atmospheric aerosols.

\section{Conclusions}

A new model of multi-component aerosol evaporation in a thermodenuder has been developed. Unlike most previous models, separate heating and denuder sections are explicitly accounted for as is the velocity profile through the denuder tube. As expected, higher temperatures are required to achieve equivalent amounts of evaporation for low volatility vs. high volatility components. A relationship between the saturation concentration and temperature has been established ( $\left.\log C_{\text {sat }} \propto 1 / T_{50}\right)$ and found to be consistent with that reported by Faulhaber (2009). The influence of $\Delta H_{\text {vap }}$ on the calculated mass thermograms has been shown to be significant; a power law was determined to best describe the relationship between temperature and $\Delta H_{\text {vap }}$ for a fixed $C_{\text {sat }}$. For low $\Delta H_{\text {vap }}$ values $(<\mathrm{ca} .100 \mathrm{~kJ} / \mathrm{mol})$ the calculated mass thermogram is very sensitive to the chosen $\Delta H_{v a p}$. Reasonable agreement is found between the calculated and observed mass thermograms for a few low-volatility dicarboxylic acids (Faulhaber et al., 2009), demonstrating that the model can be used for quantitative analysis of thermodenuder observations.

Importantly, it has been demonstrated that the inclusion of the adsorbent denuder section is crucial to understanding the behavior of "semi-volatile" aerosol $\left(1 \mu \mathrm{g} / \mathrm{m}^{3}<C_{\text {sat }}<\right.$ $1000 \mu \mathrm{g} / \mathrm{m}^{3}$ ) in thermodenuders that include an adsorbent denuder. The presence of the adsorbent denuder engenders loss of particle mass as a result of evaporation of particles as a response to stripping of the gas-phase molecules by the denuder. For lower volatility components the denuder has minimal influence at room temperature because the evaporation rates of these compounds from the particles are so low. Despite this, the denuder still serves a purpose in that it helps to limit re-condensation of the material that had evaporated in the heated section. If, however, it is instead assumed that the walls in the denuder section are in local equilibrium with the gas-phase then re-condensation is similarly lessened but further evaporation due to gas-stripping is negligible. The extent to which re-condensation influences the calculations appears to depend most acutely on the assumed loading, with a greater influence found at high loadings. Additionally, it has been shown that the assumption that equi- librium can be reached in the thermodenuder at long residence times is incorrect. The model which has been developed here can be used to provide quantitative understanding of aerosol volatility measurements of single and multicomponent aerosol made using thermodenuders.

Acknowledgements. The author thanks Jose Jimenez, Paul Ziemann and Andrey Khlystov for useful discussions and comments.

Edited by: A. Wiedensohler

\section{References}

An, W. J., Pathak, R. K., Lee, B. H., and Pandis, S. N.: Aerosol volatility measurement using an improved thermodenuder: Application to secondary organic aerosol, J. Aerosol. Sci., 38, 305314, doi:10.1016/j.jaerosci.2006.12.002, 2007.

Asa-Awuku, A., Miracolo, M. A., Kroll, J. H., Robinson, A. L., and Donahue, N. M.: Mixing and phase partitioning of primary and secondary organic aerosols, Geophys. Res. Lett., 36, L15827, doi:10.1029/2009g1039301, 2009.

Bilde, M., Svenningsson, B., Monster, J., and Rosenorn, T.: Evenodd alternation of evaporation rates and vapor pressures of C3C9 dicarboxylic acid aerosols, Environ. Sci. Technol., 37, 13711378, 2003.

Burtscher, H., Baltensperger, U., Bukowiecki, N., Cohn, P., Hüglin, C., Mohr, M., Matter, U., Nyeki, S., Schmatloch, V., Streit, N., and Weingartner, E.: Separation of volatile and non-volatile aerosol fractions by thermodesorption: instrumental development and applications, J. Aerosol Sci., 32, 427-442, 2001.

Cappa, C. D., Lovejoy, E. R., and Ravishankara, A. R.: Determination of Evaporation Rates and Vapor Pressures of Very Low Volatility Compounds: A Study of the C4-C10 and C12 Dicarboxylic Acids, J. Phys. Chem. A, 111, 3099-3109, 2007.

Cappa, C. D., Lovejoy, E. R., and Ravishankara, A. R.: Evidence for liquid-like and non-ideal behavior of a mixture of organic aerosol components, Proc. Nat. Acad. Sci., 105, 18687-18691, doi:10.1073/pnas.0802144105, 2008.

Chattopadhyay, S. and Ziemann, P. J.: Vapor pressures of substituted and unsubstituted monocarboxylic and dicarboxylic acids measured using an improved thermal desorption particle beam mass spectrometry method, Aerosol Sci. Technol., 39, 10851100, 2005.

Davidovits, P., Kolb, C. E., Williams, L. R., Jayne, J. T., and Worsnop, D. R.: Mass Accommodation and Chemical Reactions at Gas-Liquid Interfaces, 106, 1323-1354, doi:10.1021/cr040366k, 2006.

Denkenberger, K. A., Moffet, R. C., Holecek, J. C., Rebotier, T. P., and Prather, K. A.: Real-Time, Single-Particle Measurements of Oligomers in Aged Ambient Aerosol Particles, 41, 5439-5446, doi:10.1021/es0703291, 2007.

Donahue, N. M., Robinson, A. L., Stanier, C. O., and Pandis, S. N.: Coupled partitioning, dilution, and chemical aging of semivolatile organics, Environ. Sci. Technol., 40, 2635-2643, 2006.

Epstein, S. A., Riipinen, I., and Donahue, N. M.: A Semiempirical Correlation between Enthalpy of Vaporization and Saturation Concentration for Organic Aerosol, Environ. Sci. Technol., 44, 743-748, doi:10.1021/es902497z, 2010. 
Faulhaber, A. E., Thomas, B. M., Jimenez, J. L., Jayne, J. T., Worsnop, D. R., and Ziemann, P. J.: Characterization of a thermodenuder-particle beam mass spectrometer system for the study of organic aerosol volatility and composition, Atmos. Meas. Tech., 2, 15-31, doi:10.5194/amt-2-15-2009, 2009.

Gormley, P. G. and Kennedy, M.: Diffusion from a stream flowing through a cylindrical tube, Proc. Royal Irish Acad., 52, 163-169, 1949.

Grieshop, A. P., Donahue, N. M., and Robinson, A. L.: Is the gas-particle partitioning in alpha-pinene secondary organic aerosol reversible?, Geophys. Res. Lett., 34, L14810, doi:10.1029/2007GL029987, 2007.

Grieshop, A. P., Miracolo, M. A., Donahue, N. M., and Robinson, A. L.: Constraining the Volatility Distribution and Gas-Particle Partitioning of Combustion Aerosols Using Isothermal Dilution and Thermodenuder Measurements, Environ. Sci. Technol., 43, 4750-4756, doi:10.1021/es8032378, 2009.

Huffman, J. A., Ziemann, P. J., Jayne, J. T., Worsnop, D. R., and Jimenez, J. L.: Development and characterization of a fast-stepping/scanning thermodenuder for chemically-resolved aerosol volatility measurements, Aerosol Sci. Technol., 42, 395407, doi:10.1080/02786820802104981, 2008.

Huffman, J. A., Docherty, K. S., Aiken, A. C., Cubison, M. J., U1brich, I. M., DeCarlo, P. F., Sueper, D., Jayne, J. T., Worsnop, D. R., Ziemann, P. J., and Jimenez, J. L.: Chemically-resolved aerosol volatility measurements from two megacity field studies, Atmos. Chem. Phys., 9, 7161-7182, doi:10.5194/acp-9-71612009, 2009a.

Huffman, J. A., Docherty, K. S., Mohr, C., Cubison, M. J., Ulbrich, I. M., Ziemann, P. J., Onasch, T. B., and Jimenez, J. L.: Chemically-Resolved volatility measurments of organic aerosol from different sources, Environ. Sci. Technol., 43, 5351-5357, 10.1021/es803539d, 2009b.

Kalberer, M., Paulsen, D., Sax, M., Steinbacher, M., Dommen, J., Prevot, A. S. H., Fisseha, R., Weingartner, E., Frankevich, V., Zenobi, R., and Baltensperger, U.: Identification of polymers as major components of atmospheric organic aerosols, Science, 303, 1659-1662, 2004.

Kostenidou, E., Lee, B.-H., Engelhart, G. J., Pierce, J. R., and Pandis, S. N.: Mass Spectra Deconvolution of Low, Medium, and High Volatility Biogenic Secondary Organic Aerosol, Environ. Sci. Technol., 43, 4884-4889, doi:10.1021/es803676g, 2009.

Kroll, J. H., Smith, J. D., Che, D. L., Kessler, S. H., Worsnop, D. R., and Wilson, K. R.: Measurement of fragmentation and functionalization pathways in the heterogeneous oxidation of oxidized organic aerosol, Phys. Chem. Chem. Phys., 11, 8005-8014, doi:10.1039/b905289e, 2009.

Kulmala, M. and Wagner, P. E.: Mass accommodation and uptake coefficients - a quantitative comparison, 32, 833-841, 2001.
Li, Y. Q., Davidovits, P., Shi, Q., Jayne, J. T., Kolb, C. E., and Worsnop, D. R.: Mass and thermal accommodation coefficients of $\mathrm{H}_{2} \mathrm{O}(\mathrm{g})$ on liquid water as a function of temperature, J. Phys. Chem. A, 105, 10627-10634, 2001.

Marcolli, C., Luo, B. P., and Peter, T.: Mixing of the organic aerosol fractions: Liquids as the thermodynamically stable phases, J. Phys. Chem. A, 108, 2216-2224, 2004.

Pankow, J. F.: An Absorption-Model of Gas-Particle Partitioning of Organic-Compounds in the Atmosphere, Atmos. Environ., 28, 185-188, 1994.

Pratsinis, S. E., Xu, M. D., Biswas, P., and Willeke, K.: Theory for Aerosol Sampling through Annular Diffusion Denuders, J. Aerosol. Sci., 20, 1597-1600, 1989.

Sakurai, H., Park, K., McMurry, P. H., Zarling, D. D., Kittelson, D. B., and Ziemann, P. J.: Size-Dependent Mixing Characteristics of Volatile and Nonvolatile Components in Diesel Exhaust Aerosols, Environ. Sci. Technol., 37, 5487-5495, doi:10.1021/es034362t, 2003.

Saleh, R., Walker, J., and Khlystov, A.: Determination of saturation pressure and enthalpy of vaporization of semi-volatile aerosols: The integrated volume method, J. Aerosol. Sci., 39, 876-887, doi:10.1016/j.jaerosci.2008.06.004, 2008.

Saleh, R., Shihadeh, A., and Khlystov, A.: Determination of evaporation coefficients of semi-volatile organic aerosols using an integrated volume - tandem differential mobility analysis (IV-TDMA) method J. Aerosol Sci., 40, 1019-1029, doi:10.1016/j.jaerosci.2009.09.008, 2009.

Seinfeld, J. H. and Pandis, S. N.: Atmospheric chemistry and physics : from air pollution to climate change, Wiley, New York, xxvii, 1326 pp., 1998.

Smith, J. D., Cappa, C. D., Drisdell, W. S., Cohen, R. C., and Saykally, R. J.: Raman Thermometry Measurements of Free Evaporation from Liquid Water Droplets, 128, 12892-12898, doi:10.1021/ja063579v, 2006.

Wehner, B., Philippin, S., and Wiedensohler, A.: Design and calibration of a thermodenuder with an improved heating unit to measure the size-dependent volatile fraction of aerosol particles, J. Aerosol Sci., 33, 1087-1093, 2002.

Wehner, B., Philippin, S., Wiedensohler, A., Scheer, V., and Vogt, R.: Variability of non-volatile fractions of atmospheric aerosol particles with traffic influence, Atmos. Environ., 38, 6081-6090, 2004.

Winkler, P. M., Vrtala, A., Wagner, P. E., Kulmala, M., Lehtinen, K. E. J., and Vesala, T.: Mass and Thermal Accommodation during Gas-Liquid Condensation of Water, Phys. Rev. Lett., 93, 075701, doi:10.1103/PhysRevLett.93.075701, 2004. 